\title{
Practice Intentions of Family Physicians Trained in Teaching Health Centers: The Value of Community- Based Training
}

\author{
Zachary Levin, BA, Peter Meyers, MD, MPH, Lars Peterson, MD, PhD, Andy Habib, \\ and Andrew Bazemore, $M D, M P H$
}

Family medicine residents who graduate from Federally Qualified Health Center-aligned Teaching Health Center (THC) training residencies are nearly twice as likely to pursue employment in safetynet settings compared with non-THC graduates. This trend has been consistent over the past few years, suggesting that the program is fulfilling its mission to strengthen primary care in underserved settings. (J Am Board Fam Med 2019;32:134-135.)

Keywords: Family Physicians, Graduate Medical Education, Primary Health Care, Residency

The Teaching Health Center Graduate Medical Education (THC) program provides funding for residency positions that emphasize communitybased training to address health care workforce needs. ${ }^{1}$ Currently these positions are filled by over 700 medical residents in 57 programs in Federally Qualified Health Centers (FQHCs) across the United States. ${ }^{2}$ A previous study of graduating Family Medicine (FM) THC residents found that, in $2014,32.7 \%$ of THC residents intended to practice in safety net clinics, as compared with $17.8 \%$ of non-THC residents. ${ }^{3}$ This brief expands that analysis across 3 years.

Using data from a 2014 to 2016 questionnaire required of all graduating FM residents when registering for the American Board of Family Medicine certification examination, we identified graduates of THCs and where they intended to work after grad-

This article was externally peer reviewed.

Submitted 2 October 2018; revised 20 December 2018; accepted 30 December 2018.

From The Robert Graham Center, Washington, DC (ZL, AB); West Side Community Health Services, Saint Paul, MN (PM); The American Board of Family Medicine, Lexington, KY (LP); Department of Family and Community Medicine, University of Kentucky, Lexington, KY (LP); Dartmouth College, Hanover, NH (AH).

Funding: none.

Conflict of interest: Dr. Peterson is an employee of the American Board of Family Medicine.

Corresponding author: Andrew Bazemore, Robert Graham Center, 1133 Connecticut Ave NW \#1100, Washington, DC 20036 (E-mail: policy@aafp.org). uation. We then classified practice sites as safety net settings if they were FQHCs, Rural Health Clinics, public health clinics, institutional clinics, or part of the Indian Health Service.

Of 9579 graduating FM residents across 3 years, $6182(64.5 \%)$ reported future practice plans. Among the 9256 non-THC FM graduates, 5966 (64.46\%) reported practice intent and among the 323 THC FM graduates, $216(66.87 \%)$ reported practice intent. The reported practice intentions for both THC and non-THC FM residents by year are shown in Figure 1. Across the 3 years, an average of $35.6 \%$ of THC residents reported intent to work in a safety net setting, versus $18.7 \%$ of non-THC residents $(P<.01)$.

These findings suggest that the THC program is producing a cohort of family physicians likely to increase access to primary care services for vulnerable communities. Our findings are wellaligned with recent statements by both administration officials and the National Academy of Medicine, emphasizing the need for value and measurable outcomes from federal investment in graduate medical education. ${ }^{4,5}$ However, the program is small and remains funded on a shortterm basis, which leaves it perilously close to disappearing without a sustainable policy strategy for its long-term existence.

To see this article online, please go to: http://jabfm.org/content/ 32/2/134. full. 
Figure 1. Percentage of Family Medicine Residency Graduates from 2014 to 2016 intending to practice in a SafetyNet Setting after Graduation. THC, Teaching Health Center.

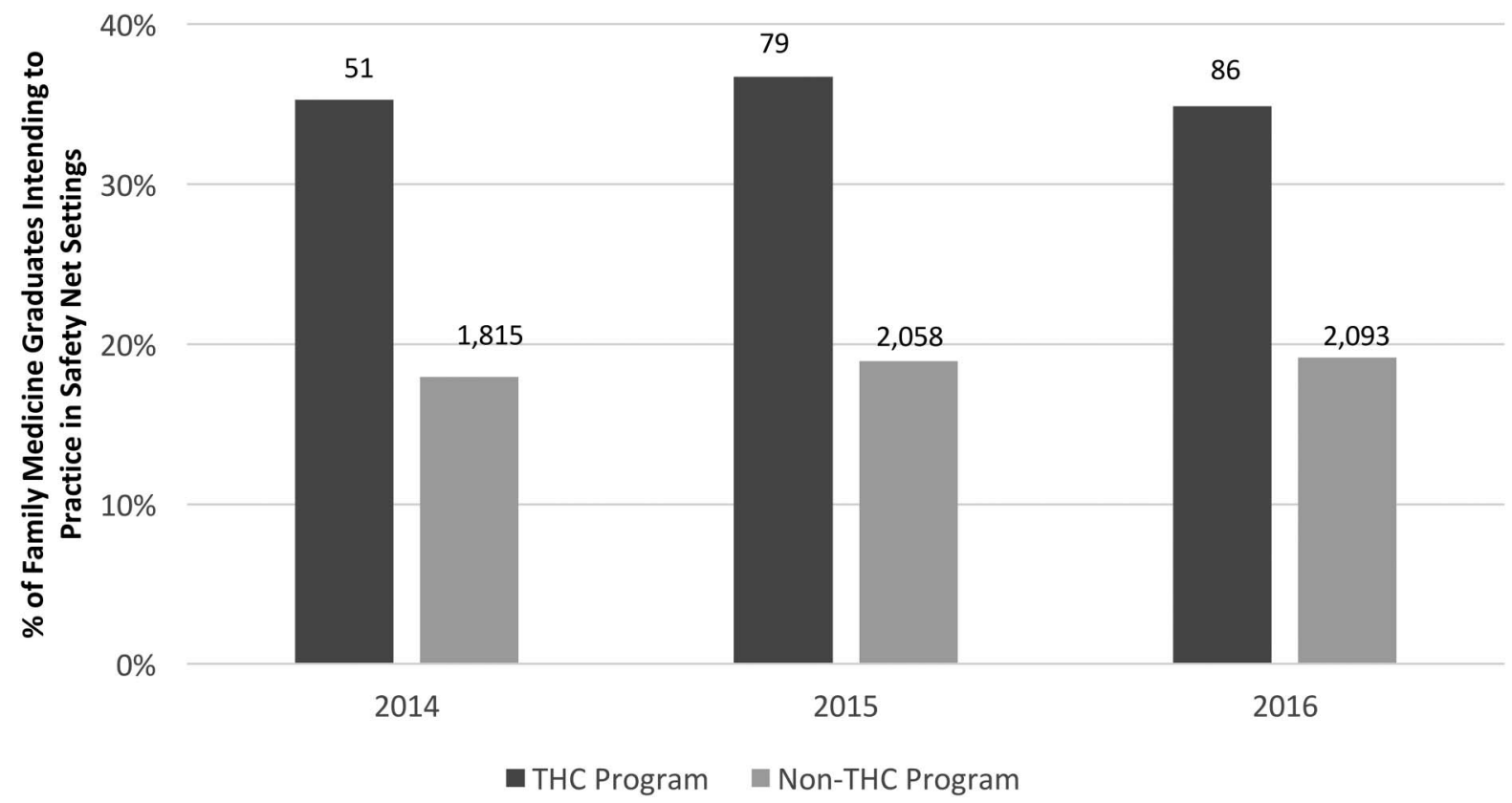

\section{References}

1. Chen C, Chen F, Mullan F. Teaching health centers: A new paradigm in graduate medical education. Acad Med 2012;87:1752-1756.

2. American Association of Teaching Health Centers. Know the facts. Available from: http://aathc.org/ know-the-facts/. Accessed May 2018.

3. Bazemore A, Wingrove P, Petterson S, Peterson L, Raffoul M, Phillips R. Graduates of teaching health centers are more likely to enter practice in the primary care safety net. Am Fam Physician 2015; 94:868.

4. U.S. Department of Health and Human Services. Remarks on Value-Based Transformation and Innovation. Speech text delivered by Alex Azar to the World Health Care Conference on May 2, 2018. Available from: https:// www.hhs.gov/about/leadership/secretary/speeches/2018speeches/remarks-on-value-based-transformation-andinnovation.html. Accessed May 2018.

5. Health and Medicine Division of the National Academies. Workshop, graduate medical education outcomes and metrics (2017). Available from: http:// www.nationalacademies.org/hmd/Activities/Workforce/ GMEoutcomesandmetrics/2017-OCT-10.aspx. Accessed May 2018. 